ARTIGO

\title{
Sensibilidade analítica em educação: sobre as potências das (auto)biografias na pesquisa- formação com professoras/es iniciantes
}

\author{
Amanda Raquel Rodrigues Pessoal (D) \\ Maria Mikaele da Silva Cavalcante" (D) \\ Wenderson Silva Oliveira"l (D) \\ Isabel Maria Sabino de Farias" (D)
}

\section{RESUMO}

Este ensaio discute a perspectiva (auto)biográfica como sensibilidade analítica em pesquisas com formação docente e desenvolvimento profissional, direcionando-se, especialmente, à pesquisa com professoras/es iniciantes na carreira. $\mathrm{O}$ debate que levantamos, fruto das discussões em nosso grupo de pesquisa, centra-se na dimensão sensível a fim de trazer contribuições para se refletir a respeito das experiências-vividas e de suas escritas, atravessadas pelos cotidianos escolares. Nessa direção, nossa defesa parte de reconhecer narrativas (auto)biográficas e suas "escrevivências" como ferramentas potentes para a compreensão dos primeiros anos da docência e de processos de indução.

\section{PALAVRAS-CHAVE}

(auto)biografia; pesquisa-formação; narrativas; professoras/es iniciantes.

'Instituto Federal do Ceará, Juazeiro do Norte, CE, Brasil.

"Universidade Estadual do Ceará, Fortaleza, CE, Brasil.

"'Rede Municipal de Educação de Sobral, Sobral, CE, Brasil. 


\title{
ANALYTICAL SENSITIVITY IN EDUCATION:THE POWER OF (AUTO)BIOGRAPHIES IN A TRAINING-RESEARCH PROCESS INVOLVING BEGINNER TEACHERS
}

\begin{abstract}
This paper discusses the (auto)biographical perspective as an element of analytical sensitivity in research studies involving teacher training and professional development, focusing on research studies with beginner teachers. The debate that we have raised, based on the discussions held in our Research Group, focuses on a sensitive dimension to help us reflect on the lived experiences and their writings, crossed by the everyday school life. In this sense, we acknowledge (auto)biographical narratives and "written experiences" as powerful tools for understanding the early years of teaching and induction processes.
\end{abstract}

KEYWORDS

(auto)biography; training-research process; narratives; beginner teachers.

\section{SENSIBILIDAD ANALITICA EN EDUCACIÓN: SOBRE LOS PODERES DE LAS (AUTO)BIOGRAFÍAS EN LA FORMACIÓN- INVESTIGACIÓN CON PROFESORES PRINCIPIANTES}

\section{RESUMEN}

Este ensayo analiza la perspectiva (auto)biográfica como sensibilidad analítica en la investigación con formación docente y desarrollo profesional, centrándose especialmente en la investigación con docentes principiantes. El debate que hemos planteado, basado en discusiones en nuestro Grupo de Investigación, se centra en la dimensión sensible, con el fin de aportar aportes para reflexionar sobre las vivencias y sus escritos, atravesados por la cotidianidad escolar. En este sentido, nuestra defensa parte de reconocer las narrativas (auto)biográficas y sus escrevivências como poderosas herramientas para comprender los primeros años de los procesos de enseñanza e inducción. 


\section{INTRODUÇÃO}

Na face do velho

as rugas são letras,

palavras escritas na carne,

abecedário do viver.

Na face do jovem

o frescor da pele

e o brilho dos olhos

são dúvidas.

Nas mãos entrelaçadas

de ambos,

o velho tempo

funde-se ao novo,

e as falas silenciadas

explodem.

\section{[...]}

[Do velho ao jovem — Conceição Evaristo, 2008, p. 51]

A memória e as histórias de vida são elementos fulcrais nas obras de Conceição Evaristo, escritora e poetisa mineira. Sua poética movimenta-se em uma perspectiva que [con]funde escrita e vida, "ou, melhor dizendo, escrita e vivência" (Evaristo, 2017a, p. 9). Nesse aspecto, a escritora-artista leva-nos a pensar narrativas como invenções, não porque não estejam comprometidas com o que aconteceu, mas entendendo que, "[...] entre o acontecimento e a narração do fato, há um espaço em profundidade, é ali que explode a invenção” (Evaristo, 2017a,p. 11). A tessitura deste texto, de certo modo, dedica-se a pensar nas possibilidades do acontecimento ${ }^{1}$, uma vez que está [co]movida pelas leituras que nos perpassaram até chegarmos nestas palavras-escritas e que também ocuparam nossas vivências como pesquisadoras, professoras, inventoras, narradoras, contadoras e ouvintes de histórias.

Tentamos sempre, em nossas caminhadas acadêmicas, [con]fundir nossas vivências com nossos escritos; deixamos muito de nós e colhemos muito de outras e outros que ora lemos e com quem ora conversamos. Esses movimentos, que são tecidos entre acontecimentos que nossas andanças pelos cotidianos das escolas-universidade-escolas provocam, permitem-nos dar novas leituras e outros sentidos à vida vivida na pesquisa em Educação. Temos buscado, do mesmo modo, enxergar nesses encontros narrativas que desestabilizam a visão estática de uma vida linear e cronológica, que singularizam o que parece ser repetitivo, evocam a pluralidade, ofertam rumos incertos para vidas cheias de certezas, poetizam nossos modos de pensar e fazer ciência e convidam-nos aos afetos múltiplos.

1 Recorremos, neste ensaio, à percepção de Foucault (2014) para entender que o acontecimento não é, por assim dizer, o que acontece, mas sim está no que acontece. $\mathrm{O}$ acontecimento configura "[...] o lugar do irracional, do impensável, daquilo que não entra e não pode entrar na mecânica e no jogo da análise, pelo menos na forma que tomaram no interior do estruturalismo" (Foucault, 2014, p. 40). 
Situamo-nos, dessa maneira, em permanente conexão com outras trajetórias, histórias e memórias. Criamos linhas de fuga e, tal como aprendemos com Deleuze e Guattari (2011), nossos rizomas são multiplicados e articulados pelos diversos saberes que convivem conosco nesses encontros. Buscamos, constantemente, desterritorializar-nos para nos livrarmos das heranças cartesianas e binárias que aprendemos com os modos de fazer ciência da Modernidade. Como o rizoma não apresenta estrutura e tampouco é fixo, pode ser conectado a qualquer ponto em qualquer momento, por isso apostamos na heterogeneidade que compõe a vida para que possamos trazer para o debate, em nossas pesquisas, essas multiplicidades.

Expandimo-nos para tentar captar a singularidade de cada palavra, gesto e ação no que acontece. Como professoras/es que somos, buscamos, por meio das narrativas de nossas/os pares, movimentar-nos numa permanente formação profissional, tecida em redes. Rizomaticamente, também, urdimos novas sensibilidades que nos fazem perceber as instituições de ensino e seus cotidianos como potências criativas e inventivas, potências múltiplas e transformadoras, que se fazem nos contatos entre os diversos corpos e subjetividades. Nilda Alves (2008, p. 16), ao movimentar-se no sentido de decifrar o complexo pergaminho das lógicas das redes cotidianas, ensina-nos que "[...] esses conhecimentos e as formas como são tecidos exigem que admitamos ser preciso mergulhar inteiramente em outras lógicas para apreendê-los e compreendê-los".

Neste ensaio, discutiremos as narrativas (auto)biográficas como sensibilidade analítica nas pesquisas-formação com professoras/es iniciantes. Entendemos as narrativas (auto)biográficas como a fabulação de vivências cotidianas que nos atravessam, tocam e transformam. Somadas a essa compreensão, tomamos de empréstimo as "escrevivências" teorizadas por Conceição Evaristo (2017a). Estas dizem respeito às narrativas escritas dessas experiências, costuradas por meio de relações individuais e coletivas ou pela via de representações simbólicas, apresentando, desse modo, uma potente possibilidade de ação, formação e transformação nas pesquisas que enfocam o desenvolvimento profissional docente, particularmente o período de iniciação à docência.

Recorremos ao termo "sensibilidade" intencionalmente, por entendermos que a formação docente é cheia de afetos. No momento em que nos lançamos como pesquisadoras/es, somos expostas/os a diversas situações que causam as mais diversas reações. São estas o frio na barriga, a fome, o sorriso na partilha do lanche, a impaciência, o choro, os olhares curiosos, os odores, os prazeres por meio do diálogo com outras e outros, escritos, gestos, símbolos e, enfim, reações que constituímos na qualidade de seres sociais e movediços. Entre outras coisas mais, sermos invadidas pelos múltiplos agenciamentos invisíveis, maneiras rebeldes que afetam nossos jeitos de produzir pesquisa nos cotidianos em que nos inserimos. São sensações diversas que só conseguimos experimentar e viver nesses mergulhos que logramos fazer nas redes de pesquisas-partilhas que tecemos ao longo de nossas trajetórias e encontros.

Nossos rizomas conectaram-se com esteio em três linhas de articulação, geograficamente localizadas na Universidade Federal do Rio de Janeiro (UFRJ), na Universidade Federal de Santa Catarina (UFSC) e na Universidade Estadual do Ceará (UECE). Juntas, essas conexões formam a rede epistemológica de uma pesquisa-formação que nomeamos Pesquisa com professores iniciantes: um estudo sobre indução 
profissional . A proposta considera a pesquisa-formação como caminho metodológico, por entender que esse processo propicia um encontro da/o sujeita/o consigo mesma/o, que pode ser potencializado por meio das narrativas (auto)biográficas, uma vez que suas reflexões unem passado e presente e, na produção de sentidos dessa união, divisam um futuro por meio dessas múltiplas conexões, linhas e leituras. Nesse esteio, o uso (Certeau, 2014) que fazemos da "escrevivência" (Evaristo, 2017a) exprime-se como uma maneira de evidenciar as identidades docentes e seus corpos, um modo de reconhecer e valorizar saberes que rompem com as "[...] monoculturas que caracterizam a sociedade contemporânea em benefício de relações mais ecológicas entre os diferentes conhecimentos, culturas e formas de expressão" (Oliveira e Geraldi, 2010, p. 25).

Acreditamos que pessoalizar e humanizar professoras/es nos permite um aprofundamento em seus processos formativo-educacionais, uma vez que "[...] estudar como o conhecimento é tecido exige que se admitam as diferenças culturais sem hierarquias, o que abre múltiplas possibilidade ao ato humano de conhecer" (Alves e Garcia, 2016, p. 12. Destaque no original). Por meio das experiências vividas no cotidiano, em movimentos dentro-fora das instituições de ensino nas quais estão inseridas/os, professoras e professores tecem, junto de outras/os tantas/os praticantes escolares, suas redes de saberes. Aprendemos com Boaventura de Sousa Santos (2002) que a ecologia de saberes é uma tentativa de superar a monocultura que permeia o saber científico, abrindo espaço para o diálogo entre vários saberes para que as vozes historicamente silenciadas emerjam e se reforcem na luta por emancipação social. Assim, abrimos espaço para evidenciar esse conjunto ecológico dos saberes que auxiliam no moto-contínuo da formação profissional, sobretudo com professoras/es iniciantes.

Distanciamento, neutralidade e objetividade são palavras que permeiam muitas das práticas de pesquisa. Por mais que elas não estejam escritas, é possível identificar suas linhas nas metanarrativas, na generalização e na tentativa de separação entre sujeito e objeto. No momento em que nos dispomos a pensar (auto)biografias na formação docente, deixamos de lado esses pilares justamente por compreendermos que somos sujeitas/os acompanhada/os das múltiplas redes que nos formaram no decorrer da vida. Ao narrar a si mesma/o, cada professora/professor toma consciência de seu lugar de sujeita/o e não objeto, [con]funde-se com a história da/o outra/o, acessa memórias e ouve a sua voz. Assim, também, começa a prestar atenção em seus processos formativos, abandonando as amarras discursivas estruturais, que insistem na ideia de capacitação para o estabelecimento de uma profissionalidade.

Nilda Alves (2016) mostra-nos uma nova maneira de compreender os conhecimentos nos cotidianos, entendendo-os com suporte na criação de redes, nas quais as/os praticantes do cotidiano (Certeau, 2014) estão ligados por fios e por meio desses entrecruzamentos tecem saberes, em vez de elaborá-los. Ao desmontar o sentido de formulação de conhecimento - que pressupõe que o sujeito é um objeto

2 Trata-se de uma pesquisa em rede, apoiada pelo Conselho Nacional de Desenvolvimento Científico e Tecnológico (CNPq) (Edital Universal 2018), que investiga a indução profissional docente no que concerne aos desafios de professoras/es de Educação Básica em seus primeiros anos de exercício profissional no contexto de redes públicas de ensino localizadas nos estados do Ceará, Rio de Janeiro e Santa Catarina. 
vazio -, o pensamento de tessitura de saberes em rede permite entender que, no permanente movimento dentro-fora das escolas-universidade-escolas, os sujeitos entrelaçam os conhecimentos, negociam as percepções de mundo e fiam linhas múltiplas que criam, do mesmo modo, múltiplos sentidos e significados para a vida.

Desse modo, ao recorrermos às narrativas, histórias e escritas de vida na formação e no desenvolvimento profissional docente, fazemo-lo porque acreditamos na força e na potências das tessituras que compõem essas múltiplas redes. Ao se enxergarem em permanentes movimentos dentro-fora dos processos educativos e em seus cotidianos, professoras/es alargam as percepções sobre educação, propõem táticas para enfrentar e resistir aos problemas que surgem e divisam novos caminhos para ensinar e para aprender. No movimento de fiar e desfiar das redes de saberes, professoras/es mergulham em suas práticas profissionais, engendram novas maneiras de pensar a si mesmas/os, pensar escola, pensar educação.

As redes de saberes são rizomáticas; elas compreendem a complexidade do conhecimento e entendem a heterogeneidade nos diversos processos de ensinar e aprender. Diferentemente do que a política oficial de formação docente tem pensado, ao operar uma imagem de desqualificação da formação docente (Farias, 2019), temo-nos esforçado para trazer à tona a força dessas redes, tentando entender as formas de se "[...] compreender como se cria o conhecimento, em todas as áreas de atividades humanas - das ciências aos movimentos sociais, do mundo do trabalho à comunicação social"(Alves,2016, p. 98).

Deleuze e Guattari (2011) ensinam-nos que qualquer ponto do rizoma pode ser conectado a outro, ou seja, não faz parte de uma raiz, unilateral e verticalizada; pelo contrário, o rizoma é espalhado e não segue um princípio hierárquico nem homogêneo. Não existem pontos, como mencionam os autores, apenas linhas. Ao partirmos das redes de saberes para compreendermos a formação e o desenvolvimento profissional de professoras/es iniciantes, reconhecemos a complexidade das lógicas que compõem essas relações. O exercício é tentar entender a formação centrada no sujeito e em suas narrativas "escreviventes" como um mapa aberto, com linhas desterritoriais entrecruzadas e, nesse sentido, posicionamo-nos na defesa de pensar-fazer (auto)biografias em pesquisas-formação. Ao mesmo tempo em que professoras/es formam redes com suas alunas e seus alunos, são formadas/os por essas mesmas redes que no cotidiano da escola se encontram, sobretudo as linhas que encontramos nas vivências das/os estudantes.

Nosso estudo centra-se na dimensão sensível a fim de trazer contribuições para refletirmos sobre o desenvolvimento profissional docente, com procedência nas experiências de vida das/os sujeitas/os iniciantes na profissão, reconhecendo sua dimensão subjetiva e discursos sobre sua formação. Entendemos como professoras/es iniciantes aquelas/es que ingressam pela primeira vez na carreira e estão nos cinco primeiros anos de profissão (Garcia, 2010). Esses primeiros anos, segundo Nono (2011, p. 19), representam um período de aprendizado intenso "[...] e influenciam não apenas a permanência do[/a] professor[/a] na carreira, mas também o tipo de professor[/a] que o[/a] iniciante virá a ser”. A iniciação, para Garcia (1999), é o período em que professoras/es passam de estudantes a profissionais - tempo marcado por tensões e pela aquisição de conhecimento e equilíbrio profissional. Segundo Huberman (2007), o desenvolvimento na carreira é um processo permeado de regressões e descontinuidades. No que se refere ao período de inserção profissional, em geral, trata-se de um 
momento marcado por ansiedade, inseguranças, medos, descobertas e aprendizagens, pois os conhecimentos adquiridos e a capacidade de articulação deles são evidenciados e julgados, o que torna esse processo de iniciação ao magistério especialmente importante.É também nesse período inicial que professoras/es começam a estabelecer suas identidades pessoais e profissionais, aprendem a ensinar ensinando.

Trazemos para o debate uma abordagem conceitual da temática até aqui delineada, fruto de reflexões realizadas nos encontros coletivos de orientação (ECO) do grupo de pesquisa Educação, Cultura Escolar e Sociedade (EDUCAS) ${ }^{3}$. Cientes dos limites deste escrito, centramos a discussão na defesa de uma formação docente movimentada por uma sensibilidade analítica que se apoie nas narrativas (auto)biográficas e nas potencialidades de suas escrituras para o acompanhamento, a formação e a compreensão dos processos de desenvolvimento profissional docente, particularmente durante o processo de iniciação à profissão de professora/professor. Esperamos, desse modo, ampliar o debate acerca das possibilidades metodológicas nas pesquisas com professoras/es iniciantes e sobre as multiplicidades do uso de narrativas no processo investigativo com (auto)formação.

\section{FORMAÇÃO DOCENTE E AS (AUTO)BIOGRAFIAS: APROXIMAÇÕES}

Em nossas pesquisas, compreendemos que o âmago da (auto)biografia é refletir sobre as histórias de vida, a sua história e a da vida da/o outra/o. Essa abordagem de pesquisa tem como objetivo produzir compreensões sobre a fala das/dos autoras/es de suas histórias e de suas experiências. Ou seja, "[...] entender a relação entre sujeito, sua trajetória e o esquema de conceitos que se produzem a partir das narrativas e dos relatos de experiências pelos quais cada um[a] passa ao longo do seu processo formativo"(Silva, 2020, p. 6). Nóvoa e Finger (2014) entendem que essa capacidade de reflexão facilita o desenvolvimento de uma sociologia holística da formação, permitindo que a formação esteja adequada à especificidade de cada pessoa. Sendo assim, podemos entender que o processo formativo centrado na compreensão de si está ligado à sua condição reflexiva e à multiplicidade de sentidos e significados que a/o sujeita/o é capaz de traduzir com base em sua experiência. Envolve, pois, um movimento de voltar-se para si mesma/o, buscando estabelecer relações entre a experiência vivida e o seu cotidiano de maneira a conduzir a experiência do professor na produção de um novo ser.

Ainda que a trajetória de um sujeito possa ser determinada pela sociedade e pela cultura, os acontecimentos e os encontros são em grande parte imprevisíveis, o que dá sentido aos aspectos interpretativos de uma narrativa, momento em que o próprio sujeito que narra atribui um novo sentido à experiência vivida. Isso sugere que não

3 O ECO caracteriza-se como atividade aglutinadora, de acompanhamento e de partilha da ação de formação e de pesquisa desenvolvida no âmbito do grupo de pesquisa EDUCAS, vinculado ao Programa de Pós-Graduação em Educação da UECE e liderado pela professora Isabel Maria Sabino de Farias. Nele, professores universitários e da Educação Básica, doutorandos, mestrandos, graduandos e demais interessados reúnem-se mensalmente para discutir suas pesquisas, estudar e debater pautas ligadas à educação e que sejam de interesse coletivo de seus integrantes. Sobre essa experiência, ver: Barros et al., 2020. 
se pode antecipar qual o peso que as experiências terão durante a trajetória de cada sujeito, principalmente por não haver condições de se saber como as experiências são tomadas pelo sujeito, salvo pela produção de sua própria narrativa, em que se volta para si e por meio dela reconstrói o vivido em um novo tempo. (Silva, 2020, p. 4)

Para Larrosa (2011), a experiência é como isso que me passa. A experiência pressupõe um acontecimento, algo que é externo ao eu. Como vimos em Foucault (2014), o acontecimento expressa-se no que acontece, logo pensar o acontecimento na experiência, para tentar entender o que me passa, é pensar no que nos perpassa, desloca nossas percepções do mundo para o que acontece conosco, e não para o que acontece a nosso redor. Além disso, pensar em como isso nos envolve desloca-nos e desterritorializa-nos. Nesse sentido, entendemos que o processo formativo docente pelas lentes da (auto)biografia é também autoformativo por não se resumir a um sistema-radícula individual e sim a um sistema por via de relações coletivas, estabelecidas nas relações sociais e culturais constituídas ao largo da vida.

Por isso, postulamos o argumento de que a formação é desterritorial. Percebemos, com nossas pesquisas-andanças, que ela não se concentra somente em um conjunto inerte de planos e ações, mas abre-se a possibilidades para o encontro-conexão de várias linhas. Como defendemos no início deste texto, ela é rizomática, vivencial, experiencial e sempre está em constante movimento. Nas palavras de Deleuze e Guattari (2011, p. 25-26),

Todo rizoma compreende linhas de segmentaridade segundo as quais ele é estratificado, territorializado, organizado, significado, atribuído, etc.; mas compreende também linhas de desterritorialização pelas quais ele foge sem parar. Há ruptura no rizoma cada vez que linhas segmentares explodem numa linha de fuga, mas a linha de fuga faz parte do rizoma. Estas linhas não param de se remeter umas às outras. É por isso que não se pode contar com um dualismo ou uma dicotomia, nem mesmo sob a forma rudimentar do bom e do mau.

Ao percebermos a formação como rizomática, entendemos que as experiências serão sempre heterogêneas e, nessa perspectiva, abandonamos o pensar sobre para praticarmos o pensar com, colocando-nos em uma busca constante de nós mesmas, como menciona Ferraço (2003), um movimento de caças-caçadoras. Estudar/Pesquisar/Pensar com, nessa perspectiva, derruba o código canônico erguido na modernidade de separação do sujeito e do objeto, quebra a lógica do dominante sobre o dominado, fratura a lógica do poder, que elege uma história única e unilateral. Fazer com é uma maneira de olhar no retrovisor de nossa história para conseguirmos perceber os vários fios da rede que tecemos ao sermos formadas e os que tecemos ao formarmos outras tantas e tantos que conosco se encontram na nossa caminhada. Nesse sentido, nossa vivência-experiência conecta o passado ao presente para divisar futuros possíveis na trajetória professoral, já que vivemos de modo intenso a heterogeneidade dessas experiências, significando-as constantemente.

Ainda em Larrosa (2011, p. 6), aprendemos que "[... ] a experiência é um movimento de ida e volta", um movimento permanente, assim como costumamos dizer. É um movimento de ida porque está exterior a nós, é uma espécie de saída de nós mesmos, 
de dentro para fora, que vai ao encontro do acontecimento. É um movimento de volta porque a experiência nos afeta e produz efeitos e sentimentos em nossa subjetividade. Nessa perspectiva, tratamos como sinonímias vivências e experiências. Essas memórias do que me acontece, no decorrer da vida vivida, mesmo efêmeras, mobilizam o caráter acontecimental que ocorre com a experiência. As vivências, com suas profundas marcas dos cotidianos, rasuram uma história única, fabulam, desmontam cronologias e linearidades, iniciam a escrita de um mapa aberto que desliza pela memória, pela história de vida, pelas emoções e sentimentos que deslocam o tempo-espaço cartesiano.

A experiência como potência transformadora vincula-se fortemente com a aprendizagem, é formadora pelo seu caráter reflexivo e simbólico estabelecido no decorrer na trajetória de vida. Numa orquestrada polifonia de compassos [as] síncronos, a experiência como aprendizagem expõe a visceralidade do vivido, ou seja, é na carne que sentiremos os atravessamentos múltiplos das singularidades do cotidiano, e também é na carne que sentimos quando atravessamos a/o outra/o. É um movimento de mergulho de dentro para dentro, como nos ensina Nilda Alves (2008). Acreditamos que a apreensão das lógicas formativas só será possível se mergulharmos inteiramente nelas. Tanto a experiência quanto a vivência nos permitirão imergir nas redes que tecemos à extensão de nossas vidas, sem que saiamos imunes desse movimento e de seus contágios, pois é nele que nos aprofundaremos para compreender nossa formação e a elaboração da nossa subjetividade.

Marie Christine Josso $(1999 ; 2006)$ afirma que as experiências formativas possuem uma relação forte com os distintos laços e nós adquiridos no percurso vivido, quer de ordem pessoal, quer profissional, que podem estabelecer elos enriquecedores ou ameaçadores para o estabelecimento de sua existencialidade, mas todos, em uma perspectiva formativa, denotam um significado. Assim, ao pensar com experiências-vivências e nas encarnaduras que deixam nas escritas da vida (ou "escrevivências"), convocamos esses laços e nós a uma narrativa singular que aponta a coletividade porque deixa à mostra as visceralidades, “[...] o lugar de enunciação de um eu coletivo, de alguém que evoca, por meio de suas próprias narrativa e voz, a história de um "nós" compartilhado" (Soares e Machado, 2017, p. 207). Acreditamos que é uma dimensão fundamental para se compreender os projetos de conhecimento que envolvem a formação no decurso da vida. É o nós que diz muito sobre o Eu e sobre as escolas praticadas por parte de cada professora e professor que nelas estão.

As narrações das histórias de vida, para Josso (2007), contribuem para uma transformação de si, afinal somos seres com elos biológicos e psicossociais, um singular-plural constituído de dimensões individuais e coletivas. Reconhecer essas características é colocar em cena a potência que permeia as experiências humanas de adultos como aprendentes, que refletem sobre suas ações e as transformam. Como nos ensinam Nóvoa e Finger (2014), pensar com base na compreensão (auto) biográfica na formação (experiências-vividas) é uma tarefa que exige um profundo respeito pelos processos experienciais-vividos das pessoas, afinal essa natureza processual heterogênea nos possibilita investigar não somente esses processos, mas também os subprocessos que compõem os bastidores da formação.

A formação docente encontra-se no âmago do processo educacional. Isso porque as/os professoras/es são profissionais que vivem diversos dilemas em seus contextos de trabalho, já que lidam com a complexidade do processo de ensino 
e aprendizagem, o que exige, além de uma constante busca de compreensão de si, da/o outra/o e dos fluxos nos quais estão inserida/os, uma contínua análise do próprio trabalho e fazer profissional. Por esse motivo, a perspectiva (auto)biográfica constitui-se como uma possibilidade metodológica singular, sobretudo no campo da formação, que se articula com a experiência-vivência pessoal e seus contextos sociais e culturais, que, ao se entrelaçarem, fazem surgir diálogos reflexivos capazes de provocar transformações no modo de ser e de agir daquelas/es que dela participam.

Pensar-fazer as relações entre narrativas (auto)biográficas e formação docente não consiste somente em fazer reemergir lembranças; é reconstituir uma história vivida e memórias marcadas com reflexões e significações constituídas ao largo dos anos e que também perpassam as memórias corporais. Longe das retóricas homogeneizantes, essas relações mostrarão as microcosmias das escolas por que passamos, o cheiro, os barulhos, os rostos das crianças e adolescentes, as professoras primárias, as cadeiras da universidade e diversos outros fragmentos que se embolam com as inventividades da narrativa. Essas memórias trarão o bumano para o centro de nossas reflexões e, ao biografarem a vida vivida, deslocaremos a cronologia que insiste em acelerar a vida cotidiana, fortaleceremos os fios que, em cada ciclo de nossa vida, deram sentido à nossa existência (Bragança, 2012).

Cada sujeito experimenta e significa o seu passado de maneiras singulares. Por isso, não é objetivo da narrativa fazer com que se realize uma reconstrução fidedigna do passado - e talvez isso nem seja possível, considerando-se que, para trazer à tona o passado, é preciso recorrer à memória, que é em sua essência falha e fragmentada, e perceber, por meio da memória e da elaboração da narrativa escrita ou falada, as reflexões que surgem e podem ressignificar realidades presentes e reverberar nas experiências futuras. E quando a memória falha? - pergunta-nos Conceição Evaristo (2017a). Surge a inventividade - responde-nos a poetisa. Certeau (2014, p. 142) diz-nos que o relato não trata apenas de ajustar-se a uma possível realidade, narrando o que efetivamente aconteceu; “[...] ao contrário, a história narrada cria um espaço de ficção. Ela se afasta do 'real"'. Sendo assim, no momento em que professoras/es começam a "escreviver" suas (auto)biografias, desmontam a cronologia e a linearidade, iniciam a escrita de um mapa aberto que desliza pela memória, pela história de vida, pelas emoções e sentimentos que deslocam o tempo-espaço cartesiano. Ao praticarem a "escrevivência", transgridem as próprias memórias porque questionam os cânones que separam corpo e mente. Os relatos trazem nos corpos as histórias de vida e nas histórias de vida os corpos, ou seja, não há uma inseparabilidade; pelo contrário, as narrativas "escreviventes" estão cheias de marcas sofridas nos corpos - narrativas que estão em constante movimento para romper silêncios homogeneizadores e hierarquias violentas (Ribeiro, 2019). Em suma, uma atividade formativa.

Por isso consideramos que é essencial perceber (auto)biografias como sensibilidade analítica potente na pesquisa com professoras/es ao estar em articulação com a formação. Essas lentes teórico-analítico-epistemológicas tornam-nos capazes de reconhecer e compreender os saberes subjetivos que fogem à formalidade, ao percebermos que as pessoas colocam em prática, como relevante no estabelecimento da profissão docente, um saber biográfico que mantém relação direta com a dimensão temporal da experiência e do agir humano (Delory-Momberger, 2006). 


\section{PENSAR COM NARRATIVAS E COM HISTÓRIAS DE VIDA}

Do que eu ouvi, colhi essas histórias. Nada perguntei. Uma intervenção fora de hora pode ameaçar a naturalidade do fluxo da voz de quem conta. Acato as histórias que me contam. Do meu ouvir, deixo só a gratidão e evito a instalação de qualquer suspeita. Assim caminho por entre vozes. Muitas vezes ouço falas de quem não vejo nem o corpo. Nada me surpreende do invisível que colho. Sei que a vida não pode ser vista só a olho nu. (Evaristo, 2017b, p. 17)

Muito falamos sobre narrativa. É uma palavra comum em vários escritos acadêmicos e que detém muitos significados. Neste ensaio, entendemos a narrativa como o ato/ ação de contar uma história (Paiva,2008), que pode ser um relato de evento real ou fictício, uma série de eventos sequenciados (ou não), um relato de acontecimentos, eventos (não) lógicos, (não) cronológicos, assim por diante. Pérez (2003, p. 101) ensina-nos que “[...] o ato de narrar sua história é um ato de conhecimento". Ao narramos nossas histórias de vida, segundo a autora, reinventamo-nos, produzimos novos sentidos aos acontecimentos, revisitamos as marcas inscritas em nossos corpos. Para Galvão (2005), as narrativas constituem-se com amparo na imbricação entre História, Discurso e Significação.

História - abrange as personagens envolvidas em determinados acontecimentos, num espaço e tempo determinados e possibilita uma primeira interpretação do que é contado; Discurso - forma específica como qualquer história é apresentada; Significação - uma interpretação de segundo nível que o ouvinte/leitor/espectador obtém a partir do inter-relacionamento da história e do respectivo discurso. (Galvão, 2005, p. 328)

Entendemos que narrativa e história não são vocábulos sinônimos, pois a narrativa, para nós, relaciona-se a um conjunto de saberes-conhecimentos que tecem uma história. Em nossas pesquisas, usamos também as narrativas como "escrevivências", memórias que relatam as histórias-experiências individuais-coletivas. Compreendemos que essa oralidade comporá um fluxo de acontecimentos diversos que transpõem o corpo e, com base neles, inventa-se a história. O relato, para Certeau (2014, p. 144), “[...] não exprime uma prática. Não se contenta em dizer um movimento. Ele o faz". Quando percebemos que o relato provoca movimento, podemos entender que ali se faz a experiência-vivida. Ou seja, na perspectiva que abordamos para a formação de professoras/es, ao dispor do relato, narrando a si mesma/o, cada sujeita/o, ao acionar essa experiência-vivida, desloca o sentido de histórias de formação, abre campo para atravessamentos e pluralidades e fratura a ideia de uma história única e também de uma narrativa singular.

Para Clandinin e Connelly (2015), a pesquisadora ou o pesquisador que se utiliza de narrativas para fazer o trabalho convive com tensões nas fronteiras do que os autores denominam de narrativa dominante (abordagem mais tradicional de pesquisa) e pensamento narrativo (abordagem da pesquisa narrativa). Nesse sentido, a racionalidade técnica que move o pensamento científico herdado na Modernidade tende a questionar modalidades de pesquisa que valorizam os modos de subjetivação de pessoas. O pensamento narrativo, assim proposto, convida pesquisadoras/ es a pensar e (re)contar as histórias de vida pautados pelo entendimento de que os 
modos de viver, as temporalidades, as práticas e processos estarão em permanente negociação por parte das/os praticantes dos cotidianos (Certeau, 2014).

As pessoas e suas ações estarão sempre em trânsito, as certezas serão provisórias e entrarão em deslocamento, os contextos não mais serão universais, mas dotados de singularidade, permeados pela pluralidade. Pensar narrativamente exige uma mudança de postura na compreensão do estudo, nos modos de lidar com aquelas e aqueles que (com)partilham conosco suas histórias, tentando superar a ideia da objetividade e a determinante busca pelos resultados empíricos cartesianos. Nessa perspectiva, ao deixarmos de lado as metanarrativas e pensarmos em pesquisas-formação com professoras/es com recurso a suas narrativas,

[...] precisamos pensar em possibilidades de discursos que possam registrar os pensamentos e palavras que transbordam pelas paredes e corredores das escolas e que nem sempre são ditos. Discursos que precisam incluir outros discursos, alternativos, e que apostam sempre nas suas próprias explicações. Discursos que ficam à espreita, esperando capturar microdiferenças que marcam as sutilezas das falas, dos gestos e imagens que habitam os cotidianos. Discursos que tentam traduzir os idiomas e os modos de ser e existir dos sujeitos cotidianos em cujos corpos encontramos registradas as marcas dos usos e das transgressões. Discursos que têm olhos distraídos que deixam de ser outras tantas coisas além daquelas que foram tornadas visíveis. Discursos que, apesar do nosso olhar congelador, precisam dar conta das identidades movediças, dos hibridismos. Discursos que, por mais vivos que possam parecer, aos olhos dos leitores/leitoras, ainda estão muito longe de captar toda a intensidade da vida cotidiana. Os cotidianos pulsam muito mais fortemente do que qualquer análise que façamos "com” eles. (Ferraço, 2003, p. 172-173)

É uma tessitura singular de subjetivações compositoras da experiência. As linhas de fuga emaranham-se para a compreensão, a interpretação e a reflexão sobre o vivido. Clandinin e Connelly (2015), ao nos ensinarem o pensar narrativamente em pesquisa com base nas diferenças entre pesquisadoras/es formalistas e pesquisadoras/es narrativas/os, explicam que não cabe na pesquisa narrativa enaltecer a teoria, mas sim utilizar a experiência de vida como potencial transformador que tem na teoria um elemento de reflexão.É uma "[...] conversa entre a teoria e a vida, ou, pelo menos, entre a teoria e as histórias de vida contidas na pesquisa"(Clandinin e Connelly,2015,p.75). A nós é caro esse movimento de conseguir apre(e)nder (com) as linhas de fuga do pensar narrativamente. Nilda Alves (2014) ensina-nos que a existência de uma multiplicidade de redes educativas nos proporciona complexas compreensões do mundo e das ações desenvolvidas profissionalmente e, desse modo, precisamos compreender essas redes em suas particularidades, tentando perceber as relações que estabelecem rizomaticamente umas com as outras. E como podemos, portanto, quebrar as metanarrativas para que nossas pesquisas sejam tecidas em rizomas?

Recorrentes vezes, apostamos como prática de pesquisa nas conversas, com o objetivo de potencializar as narrativas que circulam nossos encontros com as pessoas que conosco pesquisam. E também é por meio de conversas que podemos estabelecer outras linhas de fuga do pensar narrativamente, ao lançarmos mão desse olhar para a pesquisa-formação. Além de estabelecerem o diálogo com as teorias, "[...] o encontro e as conversas permitem tecer outras aprendizagens, a partir de 
outras lógicas e saberes na formação de professores" (Gonçalves, Rodrigues e Garcia, 2018,p. 127). Nesse entendimento, as conversas constituem-se como espaço-tempo de interações dialógicas e de negociações de sentidos que interrogam os sentidos hegemônicos ao produzirem novos significados para os saberes dos sujeitos.

Precisamos de narrativas que contribuam para a compreensão amplificada do que é e do que pode ser a realidade social na qual estamos vivendo, escamoteada e tornada invisível a "olho nu" pelas normas e regulamentos da cientificidade moderna, da hierarquia que esta estabelece entre teoria e prática e dos textos produzidos segundo tais ditames. (Oliveira e Geraldi, 2010, p. 23)

As conversas, caminhos possíveis para adentrarmos e compreendermos as potencialidades das (auto)biografias, mostram-se como inventivas e muito informativas. "Entendemos a conversa como convocação de saberes diferentes de modo não hierárquico, mas ecológico, provocando uma ecologia das diferenças que enubla até a ideia de autoria" (Süssekind e Pellegrini, 2018, p. 145). Como já dissemos no início deste texto, misturamos nossas vivências com as vivências das pessoas com quem pesquisamos, em um movimento de caça-caçador; como mencionamos em Ferraço (2003), aprendemos a multiplicar os sentidos que as falas nos apresentam. Isso nos leva à necessidade de considerar como narrativas outros movimentos que estão além das falas. Por isso, também registramos sons, imagens, movimentos corporais, objetos e outras tantas coisas que se desdobram além dessas palavras-faladas.

Com isso, os mergulhos que fazemos nas histórias de vida podem ser melhor apre(e)ndidos, porque transcendem a experiência do ouvir. Também somos atravessadas nos acontecimentos cotidianos, nossa vivência-experiencial entrelaça-se a outras tantas e produz para nós sentidos e significados que também nos formam. Como aprendemos com Conceição Evaristo (2017b) que a vida não pode ser vista somente a olho nu, esforçamo-nos para pluralizar aquilo que chamamos de metodologia, bebendo em diversas fontes para que nos aproximemos de nossas/os interlocutoras/es, nelas/es nos emaranhando. Isso nos leva à necessidade de alargar as fontes que usamos para nossas redes de conhecimento. Nesse aspecto, as fontes que buscamos estão nos mais diversificados lugares e isso requer de nós uma variedade de ações para apreendê-las.

Com base nas narrativas, como pesquisadoras/es, construiremos o que Delory-Momberger (2012) denomina de "enredamento", processo que transforma o que foi contado em uma história organizada e que traz a ideia do todo ("configuração") — uma síntese dos elementos diversos, tais como agentes, objetivos, meios, interações, circunstâncias, resultados; seria a "síntese do heterogêneo" que, por fim, irá se transformar em um elemento significativo e com sentido, produzindo efeitos sobre aquilo que relata. Assim, segundo a autora, nossa atitude precisará conseguir entrar na singularidade dos sujeitos, conforme as aberturas que vão sendo disponibilizadas durante o "processo de biografização" (Delory-Momberger, 2016), que pode estar em distintas manifestações-mentais, comportamentais, gestuais.

Ao pensarmos na (auto)biografia como sensibilidade analítica, colocamos de lado as estruturações para que possamos mergulhar no cotidiano, como defende Nilda Alves (2008). Logo, deixamos de lado questionários estruturados, respostas 
objetivas, análises estruturais, totalidades e demais categorizações que engessem pessoas para pensarmos em microcosmias que considerem as potências da vida vivida. Para nós, sensibilidade é a faculdade do sentir. A ação de sentir toma diversas direções que podemos entender como afetos manifestados na compreensão de si em uma rede de significados e sentidos que são tecidos no decorrer da história de cada qual. $\mathrm{O}$ esforço que temos em nossas pesquisas está em constantemente tentarmos apreender um objeto fugidio, por isso consideramos que precisamos estar abertas aos atravessamentos para que nossas sensações descrevam aquilo que se passa nas escolas e na vida profissional de professoras/es em início de carreira. Isso não quer dizer que refutaremos aquilo que foi feito, mas, como mapa aberto, as pesquisas - incluindo esta - precisam estar suspensas sobre aquilo que as engessa e que reduz a fala-escrita daquelas/es que conosco colaboram.

\section{PROFESSORAS/ES INICIANTES E O DESENVOLVIMENTO PROFISSIONAL: A IMPORTÂNCIA DA ESCRITA DA EXPERIÊNCIA-VIVIDA}

Consideramos como desenvolvimento profissional docente o progresso que professoras e professores vivenciam durante seu percurso profissional, composto de variadas fases e experiências-vividas acumuladas durante sua vida. Quando nos referimos ao desenvolvimento profissional, fazemos alusão, antes de um tudo, a uma pessoa que é afetada e passa por situações que vão interferir diretamente em seu pensamento e ação como docente. Dessa maneira, em nossas pesquisas, pensamos a (auto)biografia como uma possibilidade formativa para enfatizar a/o sujeita/o e valorizar o repertório constituído com base nessas experiências-vividas, como defendemos diversas vezes neste texto.

Em nossas pesquisas, focalizamos docentes em início de carreira, procurando entender como agem e reagem em relação às dificuldades da docência e suas afecções nos primeiros anos de exercício profissional.Pressupomos, para isso, ações de acompanhamento a professoras/es iniciantes que favoreçam o aprendizado da profissão, numa perspectiva contributiva à sua inserção na docência - ações essas identificadas na literatura como indução profissional (Cruz, Farias e Hobold,2020). Chamamos de indução o investimento de formação intencional, sistemática e institucionalizada em professoras/es iniciantes durante a sua inserção profissional (Nascimento, Flores e Xavier, 2019, p. 155).

Consideramos que ações institucionalizadas de indução profissional docente ${ }^{4}$ são importantes por ofertarem condições para que professoras/es estabeleçam suas trajetórias profissionais e [com]partilhem seus anseios, dúvidas, incertezas e outros afetos mais inerentes à profissão. Assim sendo, trazemos para o debate, em nossas conversas, os saberes do cotidiano, entendendo suas motivações como heterogêneas e levando em consideração os ciclos de vida profissional e as necessidades formativas de cada professora ou professor (Ferreira e Reali, 2005). Despertamos nossos sentidos como pesquisadoras/es para pensar com professoras/es sua formação, pensar por meio de suas histórias de vida. Nesse sentido, Delory-Mombeger (2006), quando destaca as

4 Alarcão e Roldão (2014) esclarecem-nos que não devemos confundir a indução profissional com o período probatório, por isso, para as autoras, trata-se de pensar uma formação em contexto de trabalho, que vai ligar a formação inicial à formação continuada. 
tendências de formação pelas histórias de vida, identifica na narrativa de si, mediante a produção da própria história, um aspecto importante para pensar a dimensão formativa da experiência de vida. Josso (2007), por sua vez, aponta que essas narrativas revelam formas e sentidos múltiplos de existencialidade, sendo por meio delas possível estabelecer relações sociais e culturais inerentes aos contextos de vida profissional e pessoal.

Em ambas as perspectivas, identificamos as linhas que revelam as potências de (trans)formação da/o sujeita/o por meio da imersão nas sensibilidades de pensar sua história de vida e também a história de vida da/o outra/o. Por isso, a sensibilidade analítica da (auto)biografia apresenta uma possibilidade-caminho a ser considerada, tendo em vista que enfoca justamente as experiências-vividas, os saberes ecológicos que se entrelaçam às subjetividades e formulam identidades docentes. Essas identidades na formação constituem configurações provisórias (Bragança, 2011), expressam-se como processuais e mutáveis, constantemente (res)significadas, assumindo novos formatos com relação à imagem de si e ao modo de estar no mundo. Para a autora, a formação depende justamente do modo como se transforma a vivência em experiência. Para nós, a indissociabilidade da vivência-experiência é o que faz com que essas identidades sejam desterritorializadas e rizomáticas.

Por isso, narrar, escrever e refletir sobre o percurso profissional é um exercício de formação que auxilia no desenvolvimento docente, pois leva a/o sujeita/o a [re]pensar suas práticas, fabular novas maneiras de fazer escola e voltar seu olhar ao seu cotidiano. Nessa direção, a pesquisa (auto)biográfica exprime-se como uma oportunidade ímpar para pensar-fazer pesquisa, formar aquele que realiza a pesquisa e o participante do estudo, considerando o conjunto de saberes que no decorrer desse processo é mobilizado. Assim, ao voltarmos nossos olhares para as experiências-vividas de professoras/es iniciantes, especialmente na Educação Básica, nossa intenção é tecer, com elas/es, estratégias para que o momento de entrada na profissão proporcione um encontro reflexivo consigo e com outro/as tantas/os que transitam e existem pelas/nas escolas. Essa colaboração em redes dá sentido às outras tantas redes que, fiadas na educação escolar, ensejam à/ao docente contar sobre as vivências-experienciadas que perpassam esse momento de inserção na carreira e, ao mesmo tempo, fornecem escuta sensivel àquelas/es que vivem momentos semelhantes na profissão.

Nossas leituras e experiências-vividas com as pesquisas permitem-nos entender que o ingresso na docência é um momento de adaptação, com intensas aprendizagens e experimentações. É um tempo perpassado por um misto de sentimentos pelo fato de a/o nova/o docente ser reconhecido/a oficialmente como um(a) profissional da área, pela experiência da primeira turma, pelo choque de realidade, pela relação com as/os pares.É um verdadeiro estágio de sobrevivência e tatear constante (Huberman,2007).É no início da carreira que professoras/es expressam suas principais dificuldades, tendo em vista que esse momento é marcado pela inserção numa nova realidade, de cunho profissional, que exige permanente ação e intervenção pedagógicas em realidades diversas. $\mathrm{A} / \mathrm{O}$ docente iniciante é, portanto, uma/um sujeita/o que requer atenção especial no processo formativo, que lhe faça pensar a sua prática diária para se constituir como profissional.

Desse modo, consideramos que é essencial perceber e potencializar as escritas das vivências-experienciadas. Afinal, ser uma/um professora/professor iniciante significa estar num lugar profissional de vulnerabilidade, em que narrar, conversar, escrever, observar e refletir são ações que ajudam a pensar a prática e a profissão em sua inteireza. $\mathrm{A} / \mathrm{O}$ professora/professor em início de carreira tem a necessidade de acolhimento, escuta e 
partilha, o que pode ser suscitado por meio da pesquisa-formação, sobretudo da "escrevivência”. Essa perspectiva teórico-analítico-epistemológica permite-nos reconhecer e compreender os diversos saberes e resistências que circundam o universo docente e que fogem à formalidade. Em nossas pesquisas, exercitamos a escuta atenta e comprometida com as diferenças. Mergulhamos em um campo de possibilidades formativas por meio das histórias que ouvimos, de luta, de superação, de preconceito, de discriminação, de afeto, tristes e felizes. São histórias-resistências que nos permitem “escreviver" novas páginas nos livros sobre formação docente. Conformam histórias atentas aos tempos/lugares de fala (Ribeiro, 2019), que buscam romper com os silêncios, hierarquias e opressões.

Apostamos na escrita dessas vivências-experienciadas ou "escrevivências" como ferramenta analítica dotada de sensibilidade, por entendermos que, no processo de indução profissional docente, as trajetórias se misturarão rizomaticamente, abrindo espaço para compreendermos os enredamentos da formação docente ao mesmo tempo em que compreendemos a nossa formação. Ao pensar nos percursos, professoras/es podem divisar seus saberes, multiplicar e dividir com seus pares, potencializando os encontros e os cotidianos das escolas como fontes inesgotáveis de formação e desenvolvimento profissional.

"Escrevivências" também se transformam em maneiras de romper com o silenciamento e apagamento dos marcadores sociais, como os de raça, gênero, sexualidade, deficiências e outros mais. A tentativa é de fazermos com que essas narrativas de professoras/es iniciantes também coloquem em pauta essas vivências e escrevam sobre elas, assumindo um compromisso com a desmarginalização de determinados corpos, a descolonização dos modos de fazer pesquisa e com a necessidade de promovermos a justiça social para aquelas e aqueles que existem e resistem nos mais diversos espaços educativos. Se pesquisadoras e pesquisadores com narrativas são fortemente (auto)biográficos, como afirmam Clandinin e Connelly (2015),

[...] escreviver significa, nesse sentido, contar histórias absolutamente particulares, mas que remetem a outras experiências coletivizadas, uma vez que se compreende existir um comum constituinte entre autor/a e protagonista, quer seja por características compartilhadas através de marcadores sociais, quer seja pela experiência vivenciada, ainda que de posições distintas. (Soares e Machado, 2017, p. 206)

Nesse sentido de "escreviver", a experiência do Eu conecta-se diretamente com a experiência da/o Outra/o, sem subalternizá-la/o, dominá-la/o, hierarquizá-la/o ou categorizá-1a/o. "Escreviver" desdobra a pesquisa narrativa e (auto)biográfica ao combinar os termos pessoal e social, o passado-presente-futuro, os tempos-espaços (Clandinin e Connelly, 2015) com as diferenças 5 . O uso que fazemos dessas ferra-

5 Quando nos referimos a Outro/a ou à construção de Outridade, falamos de relações de poder entre indivíduos, sem considerar, entretanto, que o poder provenha de um lugar específico. Pensamos em como o sujeito cria o objeto, exotizando-o, colocando-o como diferente. Nesse aspecto, partimos de Avtar Brah (2006) para entender que o que chamamos de diferença parte das tessituras de relações sociais, pensando a diferença como constituição e organização sistematizada por meio dos discursos econômicos, culturais e políticos, além das práticas institucionais. Um grupo mobiliza esse conceito ao tratar da genealogia das experiências coletivas, esquadrinhando o que seriam o "nós" e o "eles" como modo de diferenciação, sempre imbuído de poder. Aqui, evocamos a diferença como potencialidade, com o intuito de quebrar as exclusões historicamente sistematizadas nas relações sociais brasileiras. 
mentas ajuda-nos a compreender os aspectos subjetivos que compõem o desenvolvimento profissional de professoras/es iniciantes. Nesse aspecto, ao acionarmos as "escrevivências", fazemo-lo porque acreditamos que nelas as/os sujeitas/os deslocam as totalizações e abrem espaço para que vejamos as microcosmias de seus cotidianos. Nessas relações ecológicas, alargamos a compreensão sobre as possibilidades narrativas e das próprias histórias de vida. Começamos a prestar atenção no tempo-espaço em que a pesquisa-formação se desenvolve, nas imagens, nas expressões do rosto enquanto se fala, no tom de voz, nos cheiros ao redor, nas roupas, nas fotografias que marcaram momentos importantes. É o convite para "[...] descobrir/inventar novos modos de ver/ler/ouvir/sentir o mundo e de narrá-lo e aos diferentes fazeres/saberes/valores e emoções que nele circulam e dialogam" (Oliveira e Geraldi, 2010, p. 19).

Pensar com narrativas e com histórias de vida convoca-nos ao mergulho nos processos docentes que estão para além daquilo que é dito enquanto os gravadores de voz estão ligados. Descobrimos a riqueza dos diálogos e ações que escapam das liturgias montadas para pesquisas - como a gravação, os cadernos de anotação ou as fotografias feitas por nós. Nos mergulhos nas histórias de vida por meio das narrativas, procuramos ter o cuidado de não reduzir as conversas a relatórios qualitativos, esforçamo-nos para que elas sejam tratadas como ferramentas principais para pensar as práticas educativas e como os saberes dos professores iniciantes se articulam nelas, em como as tessituras de redes são realizadas nos diversos contextos que pesquisamos.

Narramos a vida e "literaturizamos" a ciência, como nos ensina Nilda Alves (2008). Ao trazermos para o debate as histórias de vida e o uso das conversas nas "escrevivências", reforçamos essas ações como sensibilidades analíticas que colocam de lado as estruturações e nos permitem mergulhar nos cotidianos das/os docentes iniciantes que conosco caminham nas pesquisas-formação. Como sensibilidade analítica, as escritas desses processos (auto)biográficos sugerem uma compreensão das narrativas como possibilidade de visibilizar a voz de professoras/es, suas experiências, aprendizagens, percepções e sentimentos. Significa dizer, ainda, que essa é uma alternativa potente a ser utilizada com professoras/es que estão vivenciando os seus primeiros anos de docência, por ensejar nessas/es docentes narrativas em meio a um cenário difícil, em que costumam ser subestimadas/os e pouco escutadas/os. (Garcia, 1999). Ao falar de si, as/os professoras/es iniciantes produzem novos significados para as suas experiências, ressignificam suas aprendizagens e refletem sobre a sua prática. É um processo que instiga a formação, levando a (re)pensar conceitos e ações.

\section{EM DEFESA DAS NARRATIVAS, AS CONSIDERAÇÕES FINAIS...}

Neste escrito, procuramos tecer elementos reflexivos sobre a importância das narrativas (auto)biográficas como sensibilidade analítica nas pesquisas com professoras/ es iniciantes em processos de indução. Nossa defesa pelas narrativas parte da compreensão que adota um pensar científico que rompe com o distanciamento sujeito-objeto e nos aproxima de relações sensíveis, capazes de afetar a condição humana de professoras e professores e transformar as narrativas em momentos de encontro consigo e com outras/os. Nessa direção, (auto)biografias são fontes que trazem sensibilidade, empatia e aprendizagem para aquelas/es que participam desse coletivo em pesquisa. 
Caminhamos no sentido de pluralizar experiências-vividas formativas, tentando apreender aquilo que passa despercebido aos ouvidos desatentos. Isso nos convida a colocar em xeque os binarismos, abrindo caminho para a multiplicidade, razão por que tratamos em nossas pesquisas a formação docente como rizomática. Desse modo, entendemos que é preciso deixar que sejamos tomadas/os pelo cotidiano ao redor e,com amparo nessas contingências, compreender que, para se pesquisar com os cotidianos, precisamos estar "[...] abertos e prontos a incorporar, interrogar, analisar, buscar compreender tudo o que nos chega, desses 'espaçostempos', nos seus tão diferentes acontecimentos, através de todos os nossos sentidos"(Andrade, Caldas e Alves, 2019,p.24).Esse movimento também é de entendimento das diferenças em curso nas escolas cotidianas.

Estamos abertas/os, como investigadoras/es e professoras/es, às vivências-experienciadas que nos chegam; dispostas a ouvir, cheirar, tocar, entre outras coisas mais, a sermos tomadas pelos múltiplos agenciamentos invisíveis e narrativas rebeldes que afetam as maneiras de tecer formação nos cotidianos escolares. Nesse aspecto, o trabalho com narrativas (auto)biográficas e "escrevivências" de professoras/es convida-nos a interrogar as verdades constituídas e as teorias que se dispõem a investigar essas verdades, para que se monte a verdade. Isso nos leva a pensar na necessidade de interrogar, com frequência, os conhecimentos que adquirimos sobre formação docente e os expedientes analíticos que usamos para conseguir compreendê-la. Passamos, desse modo, a entender a formação como um devir, que está sempre em continuidade e se dá em multiplicidades e acontecimentos.

Apostamos nas narrativas experienciadas por meio das (auto)biografias e das "escrevivências" por acreditarmos que são potencialidades nas pesquisas que desenvolvemos com professoras/es iniciantes. Narrar a vida, "literaturizá-la" e "escrevivê-la" são movimentos de romper com o anonimato ao darem voz, vez, cor, expressão e carne para as/os sujeitas/os com quem pesquisamos.É perceber que, para nós, narrativas estão para além das palavras faladas, são um desafio a pensar maneiras de pesquisar que estejam comprometidas com uma transformação social, empenhadas em largar os jargões acadêmicos para alinharem-se à simplicidade textual, à simplicidade do diálogo ao conversar.

As reflexões aqui trazidas são frutos de nossas discussões nas orientações coletivas, nas redes que [com] partilhamos no grupo de pesquisa. Refletem os movimentos de resistências que fazemos às prescrições regulamentares que visam ao assujeitamento de sujeitas/os docentes em início de formação profissional. Se, por um lado, entendemos o início da carreira docente como um período de incertezas, medos, inseguranças, por outro, defendemos o argumento de que esse período também é o momento em que professoras/es se descobrem, tecem seus primeiros fios e entrelaçam-nos com várias tramas que passam pelos cotidianos das escolas.

Desse modo, inventamos novas maneiras de pensar a pesquisa-formação com professoras/es iniciantes, maneiras que valorizam os lugares de fala, os rizomas, as redes, os saberes ecológicos e também as inventividades. Valorizamos a resistência docente, as práticas e as teorias que se manifestam nas ações e nas reações que essas/es sujeitas/os realizam nos cotidianos escolares; cotidianos que "escrevivem" narrativas (auto)biográficas, que mostram as encarnaduras das experiências-vividas plenas de multiplicidades. Os processos de indução levam professoras/es a refletir sobre suas práticas, sobre os limites e possibilidades dessas práticas. Por isso, acreditamos na força e na potência de nossas produções, porque ecoam acontecimentos, ecoam as vozes que se fazem presentes muitas vezes em anonimato. 
Assim, encerramos este texto problematizando a ideia de que, para pesquisar com professoras/es iniciantes e suas narrativas (auto)biográficas,é exigido que multipliquemos as linhas, que apreendamos as vibrações corporais. Ao voltarmos nossos olhos para as narrativas (auto)biográficas de professoras/es e seus cotidianos, estamos interessadas/os naquilo que escapa à oficialidade, estamos comprometidas/os com as redes, saberes e fazeres, com as movimentações dentro-fora das escolas-universidade-escolas. Com isso, esperamos que esse mapa aberto enseje novas linhas de fuga, outras conversas e renovadas problematizações.

\section{REFERÊNCIAS}

ALARCÃO,I.; ROLDÃO,M.C.Um passo importante no desenvolvimento profissional dos professores: o ano de indução. Revista Brasileira de Pesquisa sobre Formação Docente, Belo Horizonte, v. 6, n. 11, p. 109-126, 2014. Disponível em: https:// revformacaodocente.com.br/index.php/rbpfp/article/view/108. Acesso em: 8 dez. 2021. ALVES, N. Decifrando o pergaminho: os cotidianos das escolas nas lógicas das redes cotidianas. In: OLIVEIRA, I. B.; ALVES, N. G. Pesquisa nos/dos/com os cotidianos das escolas: sobre redes de saberes. 3. ed. Petrópolis: DP et Alii, 2008. p. 15-38.

ALVES, N. Sobre a existência de currículos em redes. In: NEFFA, E.; CAVALCANTE, D. K.; MELLO, M. B. (orgs.). Educação ambiental: reflexões político-pedagógicas. Rio de Janeiro: MRA2, 2014. p. 25-49.

ALVES, N. Tecer conhecimento em rede. In: ALVES, N.; GARCIA, R. L. O sentido da escola. 6. ed. Petrópolis: DP et Alii, 2016. p. 91-100.

ALVES, N.; GARCIA, R. L. Para começo de conversa. In: ALVES, N.; GARCIA, R. L. O sentido da escola. 6. ed. Petrópolis: DP et Alii, 2016, p. 8-14.

ANDRADE, N.; CALDAS, A. N.; ALVES, N. Os movimentos necessários às pesquisas com os cotidianos: após muitas "conversas" acerca deles. In: OLIVEIRA, I. B.; PEIXOTO, L. F.; SÜSSEKIND, M. L. (orgs.). Estudos do cotidiano, currículo e formação docente: questões metodológicas, políticas e epistemológicas. Curitiba: CRV, 2019.p. 19-46.

BARROS, J. L. C.; FARIAS, I. M. S.; RODRIGUES, H. C. A.; FARIAS, M. S. Contribuição dos encontros de orientação coletiva (ECO) na formação de profissionais docentes. Areté, Manaus, v. 13, p. 1-15, 2020. Disponível em: http://periodicos.uea. edu.br/index.php/arete/article/view/1837. Acesso em: 8 dez. 2021.

BRAGANÇA, I. F. S. Sobre o conceito de formação na abordagem (auto)biográfica. Educação, Porto Alegre, v. 34, n. 2, p. 157-164, 2011.

BRAGANÇA, I. F. S. Histórias de vida e formação de professores: diálogos entre Brasil e Portugal. Rio de Janeiro: EdUERJ, 2012.

BRAH, A. Diferença, diversidade, diferenciação. Cadernos Pagu, Campinas, n. 26, p. 329-276, 2006. https://doi.org/10.1590/S0104-83332006000100014

CERTEAU,M.A invenção do cotidiano: 1. Artes de fazer.22. ed. Petrópolis: Vozes, 2014. CLANDININ, D. J.; CONNELLY, M. Pesquisa narrativa: experiências e história na pesquisa qualitativa. 2. ed. Uberlândia: EDUFU, 2015. 
CRUZ, G. B.; FARIAS, I. M. S.; HOBOLD, M. S. Indução profissional e o início do trabalho docente: debates e necessidades. Revista Eletrônica de Educação, São Carlos, v. 14, p. 1-15, 2020. http://doi.org/10.14244/198271994149

DELEUZE, G.; GUATTARI, F. Mil platôs. 2. ed. São Paulo: Editora 34, 2011.

DELORY-MOMBERGER, C. Formação e socialização: os ateliês biográficos de projeto. Educação e Pesquisa, São Paulo, v. 32, n. 2, p. 359-371, 2006. https://doi. org/10.1590/S1517-97022006000200011

DELORY-MOMBERGER, C. Abordagens metodológicas na pesquisa biográfica. Revista Brasileira de Educação, Rio de Janeiro, v. 17, n. 51, p. 523-740, 2012. Disponível em: https://www.scielo.br/pdf/rbedu/v17n51/02.pdf. Acesso em: 8 dez. 2021.

DELORY-MOMBERGER, C. A pesquisa biográfica ou a construção compartilhada de um saber do singular. Revista Brasileira de Pesquisa (Auto)biográfica, Salvador, v. 1, n. 1, p.133-147, 2016. https://doi.org/10.31892/rbpab2525-426X.2016.v1.n1.p133-147 EVARISTO, C. Poemas da recordação e outros movimentos. Belo Horizonte: Nandyala, 2008.

EVARISTO, C. Becos da memória. 3. ed. Rio de Janeiro: Pallas, 2017a.

EVARISTO, C. Histórias de leves enganos e parecenças. 5.ed. Rio de Janeiro: Malê,2017b. FERRAÇO, C. E. Eu, caçador de mim. In: GARCIA, R. L (org.). Método: pesquisa com o cotidiano. Rio de Janeiro: DP\&A, 2003. p. 157-175.

FERREIRA, L. A.; REALI, A. M. M. R. Aprendendo a ensinar e a ser professor: Contribuições e desafios de um programa de iniciação à docência para professores de Educação Física. In: REUNIÃO NACIONAL DA ASSOCIAÇÃO NACIONAL DE PÓS-GRADUAÇÃO E PESQUISA EM EDUCAÇÃO, 28., 2005, Caxambu. Anais [...]. Caxambu: ANPEd, Oct.16-19, 2005. p. 1-17. Disponível em: https://anped. org.br/biblioteca/item/aprendendo-ensinar-e-ser-professor-contribuicoes-e-desafiosde-um-programa-de. Acesso em: 8 dez. 2021.

FOUCAULT, M. Microfísica do poder. 28. ed. Rio de Janeiro: Paz e Terra, 2014.

GALVÃO, C. Narrativas em educação. Ciência e Educação, Bauru, v. 11, n. 2, p. 327345, 2005. https://doi.org/10.1590/S1516-73132005000200013

GARCIA, C. M. Formação de professores: para uma mudança educativa. Porto: Porto Editora, 1999.

GARCIA, C.M. O professor iniciante, a prática pedagógica e o sentido da experiência. Revista Brasileira de Pesquisa sobre Formação Docente, Belo Horizonte, v. 2, n. 3, p. 11-49, 2010. Disponível em: https://revformacaodocente.com.br/index.php/rbpfp/ article/view/17. Acesso em: 8 dez. 2021.

GONÇALVES, R. M.; RODRIGUES, A.; GARCIA, A. F. L. A conversa como princípio metodológico para pensar a pesquisa e a formação docente. In: RIBEIRO, T.; SOUZA, R.; SAMPAIO, C. S. Conversa como metodologia de pesquisa: por que não? Rio de Janeiro: Ayvu, 2018. p. 119-142.

HUBERMAN, M. O ciclo de vida profissional dos professores. In: NÓVOA, A. (org.). Vidas de professores. Porto: Porto Editora, 2007. p. 31-61. 
JOSSO, M. C. História de vida e projeto: a história de vida como projeto e as "histórias de vida" a serviço de projetos. Educação e pesquisa, São Paulo, v. 25, n. 2, p. 11-23, 1999. https://doi.org/10.1590/S1517-97021999000200002

JOSSO, M. C. As figuras de ligação nos relatos de formação: ligações formadoras, deformadoras e transformadoras. Educação e Pesquisa, São Paulo, v. 32, n. 2, p. 373383, 2006. https://doi.org/10.1590/S1517-97022006000200012

JOSSO, M. C. A transformação de si a partir da narração de história de vida. Educação, Porto Alegre, n. 3, p. 413-438, 2007. Disponível em: https://wp.ufpel.edu.br/gepiem/ files/2008/09/a_tranfor2.pdf. Acesso em: 8 dez. 2021.

LARROSA, J. Experiência e alteridade em educação. Revista Reflexão e Ação, Santa Cruz do Sul, v. 19, n. 2, p. 4-27, 2011. https://doi.org/10.17058/rea.v19i2.2444

NASCIMENTO, M. G.; FLORES, M. J. B. P.; XAVIER, D. B. Indução profissional docente: desafios e tensões no contexto de uma política pública. Currículos sem Fronteiras, S. l., v. 19, n. 1, p.151-166,2019. Disponível em: https://www.curriculosemfronteiras.org/ vol19iss1articles/nascimento-flores-xavier.pdf. Acesso em: 8 dez. 2021.

NONO, M. A. Professores iniciantes: o papel da escola em sua formação. Porto Alegre: Mediação, 2011.

NÓVOA, A.; FINGER, M. (orgs.). O método (auto)biográfico e a formação. 2. ed. Natal: EDUFRN, 2014.

OLIVEIRA, I. B.; GERALDI, J. W. Narrativas: outros conhecimentos, outras formas de expressão. In: OLIVEIRA, I. B. (org.) Narrativas: outros conhecimentos, outras formas de expressão. Petrópolis: DP et Alii, 2010. p. 13-28.

PAIVA, V. L. M. O. P. A pesquisa narrativa: uma introdução. Revista Brasileira de Linguística Aplicada, Belo Horizonte, v. 8, n. 2, 2008. Disponível em: https://www. scielo.br/pdf/rbla/v8n2/01.pdf. Acesso em: 8 dez. 2021.

PÉREZ, C. L. V. Cotidiano: histórias(s), memória e narrativa - uma experiência de formação continuada de professoras alfabetizadoras. In: GARCIA, R. L. (org.). Método: pesquisa com o cotidiano. Rio de Janeiro: DP\&A, 2003. p. 97-118.

RIBEIRO, D. Lugar de fala. São Paulo: Pólen, 2019.

SANTOS, B. S. Para uma sociologia das ausências e uma sociologia das emergências. Revista Crítica de Ciências Sociais, Coimbra, n. 63, p. 237-280, 2002. https://doi. org/10.4000/rccs. 1285

SILVA, F. O. Tessituras constitutivas da abordagem (auto)biográfica como dispositivo de pesquisa qualitativa. Revista Práxis Educativa, Ponta Grossa, v. 15, n. 1, p. 1-15, 2020. https://doi.org/10.5212/PraxEduc.v.15.12960.006

SOARES, L.V.; MACHADO, P. S. "Escrevivênvias” como ferramenta metodológica na produção de conhecimento em psicologia social.Psicologia Política, Florianópolis, v. 17, n. 39, p. 203-219, 2017. Disponível em: http://pepsic.bvsalud.org/scielo.php?script=sci_ abstract\&pid=S1519-549X2017000200002\&lng=pt\&nrm=iso. Acesso em: 8 dez. 2021. SÜSSEKIND, M. L.; PELEGRINI, R. Os ventos do norte não movem moinhos... In: RIBEIRO, T.; SOUZA, R.; SAMPAIO, C. S. Conversa como metodologia de pesquisa: por que não? Rio de Janeiro: Ayvu, 2018. p. 143-162. 


\section{SOBRE OS AUTORES}

Amanda Raquel Rodrigues Pessoa é doutoranda em Educação pela Universidade Estadual do Ceará (UECE). Professora do Instituto Federal do Ceará (IFCE).

E-mail: amandampb@hotmail.com

Maria Mikaele da Silva Cavalcante é doutoranda em Educação pela Universidade Estadual do Ceará (UECE). Professora da mesma instituição. E-mail: mikaele262009@hotmail.com

Wenderson Silva Oliveira é doutorando em Educação pela Universidade Estadual do Ceará (UECE). Professor da Rede Municipal de Educação de Sobral.

E-mail: wendoliveira@gmail.com

Isabel Maria Sabino de Farias é doutora em Educação Brasileira pela Universidade Federal do Ceará (UFC). Professora da Universidade Estadual do Ceará (UECE).

E-mail: isabelinhasabino@yahoo.com.br

Conflitos de interesse: Os autores declaram que não possuem nenhum interesse comercial ou associativo que represente conflito de interesses em relação ao manuscrito.

Financiamento: $\mathrm{O}$ estudo não recebeu financiamento.

Contribuições dos autores: Administração de Projetos, Análise Formal, Conceituação, Escrita - Primeira Redação, Escrita - Revisão e Edição, Investigação: Pessoa, A. R. R.; Cavalcante, M. M. S.; Oliveira, W. S.; Farias, I. M. S.

Recebido em 25 de outubro de 2020 Aprovado em 9 de abril de 2021 